\title{
Factors associated with elevated low- density lipoprotein cholesterol levels among hill tribe people aged 30 years and over in Thailand: a cross-sectional study
}

Niwed Kullawong ${ }^{1}$, Tawatchai Apidechkul ${ }^{1,2^{*}}$ (B), Panupong Upala ${ }^{2}$, Ratipark Tamornpark ${ }^{1,2}$, Vivat Keawdounglek , Chanyanut Wongfu', Fartima Yeemard ${ }^{2}$, Siriyaporn Khunthason ${ }^{1,2}$ and Chalitar Chomchoei $^{3}$

\begin{abstract}
Background: Low-density lipoprotein cholesterol (LDL-C) is one of the most important types of cholesterol and has an impact on health. Certain lifestyle and dietary habits in different populations may leads to increased levels of LDL-C, particularly among those with poor education and economic statuses, such as hill tribe people in Thailand. This study aimed to estimate the prevalence of and determine the factors associated with high LDL-C levels among hill tribe people in northern Thailand.
\end{abstract}

Methods: A cross-sectional study was performed to gather information from six main hill tribe populations: Akha, Lahu, Hmong, Yao, Karen, and Lisu. Individuals who were aged over 30 years and living in 30 selected hill tribe villages were invited to participate in the study. A validated questionnaire and 5-mL blood specimens were used to obtain data. Correlation analyses, chi-square tests, t-tests, and logistic regression were used to detect correlations and associations.

Results: A total of 2552 participants were recruited into the study; $65.9 \%$ were females, and $64.1 \%$ were aged younger than 60 years old. Approximately $69.6 \%$ of participants had abnormal LDL-C levels; $33.6 \%$ had above-optimal levels, $24.3 \%$ had borderline high levels, $8.0 \%$ had high levels, and 3.7\% had very high levels. A total of $17.4 \%$ of participants had low high-density lipoprotein cholesterol (HDL-C) and high LDL-C levels, while $14.9 \%$ had high triglyceride and LDL-C levels. After controlling for sex, age, religion, education, annual family income, and marital status in the multivariate model, three variables were found to be associated with high LDL-C levels: occupation, the amount of lard used in daily cooking, and glycated hemoglobin (HbA1c). Those who were working as agriculturalists had a 1.34-fold greater chance of having abnormal $\mathrm{LDL}-\mathrm{C}$ than traders and others $(95 \% \mathrm{Cl}=1.09-1.34)$. Those who used moderate and high quantities of lard in their daily cooking had a 1.45 -fold $(95 \% \mathrm{Cl}=1.15-1.82)$ and 1.31 -fold $(95 \% \mathrm{Cl}=1.04-1.68)$ greater likelihood of having abnormal LDL-C levels than those who used low quantities, respectively. Those who had abnormal HbA1c levels were less likely to develop abnormal LDL-C levels than those who had normal HbA1c levels ( $A O R=0.69,95 \% \mathrm{Cl}=0.51-92$ ).

\footnotetext{
* Correspondence: Tawatchai.api@mfu.ac.th; tk2016ms@gmail.com

'School of Health Science, Mae Fah Luang University, Chiang Rai, Thailand

${ }^{2}$ Center of Excellence for The Hill tribe Health Research, Mae Fah Luang University, Chiang Rai, Thailand

Full list of author information is available at the end of the article
} 
(Continued from previous page)

Conclusions: Effective public health programs that do not conflict with the cultures of hill tribes are urgently needed, particularly programs encouraging the use of small quantities of lard for daily cooking practices.

Keywords: Low-density lipoprotein cholesterol, Hill tribe, Prevalence, Factors associated

\section{Introduction}

Low-density lipoprotein cholesterol (LDL-C) is one of the main lipids that directly reflects individual health [1]. The World Health Organization (WHO) reported that elevated LDL-C levels was estimated to result in 2.6 million deaths (4.5\% of total) and 29.7 million disability-adjusted life years (DALYs) [1]. Elevated LDL-C levels has been clearly identified as a risk factor for cardiovascular diseases (CVDs) [2]. CVDs are the leading cause of death globally, killing 17.9 million people in 2016 [2]. More seriously, three-fourths of CVD-related deaths were reported in lowand middle-income countries, including Thailand [2], particularly poor economic population [3]. There are several factors that contribute to CVD development, particularly daily dietary patterns, health behaviors [4], and LDL-C levels [5], especially in people living in developing countries [6]. A large budget is required for CVD treatment and care; however, prevention is highly effective if the risk factors in a certain population are clearly known [7].

The United Nations (UN) reported that Thailand had 69 million people with a gross domestic product (GDP) of 455,303 million US\$ in 2019 [8], which is one of the upper-middle income countries [9]. The Thailand World Health Organization (WHO) reported that more than 400,000 deaths occurred in Thailand in 2016, and 23.0\% of the deaths were due to CVDs [10]. In 2018, the Ministry of Public Health, Thailand reported that 432,943 cases of CVDs were being treated, and 2 CVD-related deaths per hour were reported [11]. The government of Thailand usually allocates a budget of $6.5 \%$ of the GDP annually [12] for the care and treatment of CVDs and their complications throughout the health care system, particularly CVDs affecting people who are living in poverty, such as the hill tribe people in northern Thailand.

In the last century, hill tribe people have migrated from South China to Thailand, especially to northern regions such Chiang Rai Province [13]. The WHO reported that approximately 4 million hill tribe people lived in Thailand in 2018 [14]. There are six main groups: Akha, Lahu, Hmong, Yao, Karen, and Lisu. In 2018, a total of 749 hill tribe villages were located in Chiang Rai Province, with a population of approximately 350,000 people [15]. Many hill tribe villages in Thailand are located approximately $500-1500 \mathrm{~m}$ above the mean sea level [13]. Therefore, the average environmental temperature is lower than $25^{\circ} \mathrm{C}$ in the whole year [13]. Each tribe has its own culture and lifestyle habits, especially in regard to daily cooking practices. Pork is the most favored meat among hill tribe members [16]. Almost all hill tribe members work in the agricultural sector and favor traditional crops to support their family members [16-18]; additionally, a large proportion of the hill tribes in Thailand live below the poverty level [19]. However, there is little biomedical information on elevated LDL-C levels among the hill tribe population in Thailand.

Therefore, this study aimed to estimate the prevalence of and factors associated with elevated LDL-C levels among hill tribe individuals aged 30 years and over.

\section{Methods}

A cross-sectional study was performed to collect data from the participants. The study was conducted in Chiang Rai Province, Thailand. Members of the six main hill tribes, Akah, Lahu, Hmong, Yao, Karen, and Lisu, who lived in Chiang Rai Province composed the study population. In 2018, there were 749 different villages in Chiang Rai Province, Thailand: 316 Lahu villages, 243 Akha villages, 63 Yao villages, 56 Hmong villages, 36 Karen villages, and 35 Lisu villages [15]. Five villages of each tribe were randomly selected for inclusion in the study, for a total of 30 villages. Hill tribe people aged 30 years and over were the target population. However, those who could not provide essential information regarding the study protocols and those who did not follow a 12-h fasting were excluded from the study.

The sample size was calculated according to the standard formula of a cross-sectional study: $n=\left[\mathrm{Z}_{\alpha / 2} \mathrm{PQ}\right] / \mathrm{e}^{2}$, where $Z_{\alpha / 2}=1.96, P=0.30$ [20], $Q=0.70$, and $e=0.05$; after adding $10 \%$ to account for any error in the study, 2132 participants were needed for the analysis.

A questionnaire and $5 \mathrm{~mL}$ blood specimens were used as the research instruments. The questionnaire was developed from a literature review and through discussion with health care professionals who were working in health institutes in hill tribe villages. Finally, there were 4 parts of the final version of the questionnaire. In the first part, 9 questions were used to collect the general information of the participants, such as age, sex, education, occupation, income, etc. In the second part, 10 questions were used to ask about the health behaviors and substance use of the participants, such as exercise, amount of salt used for daily cooking, amount of lard used in daily life, smoking, alcohol use, and methamphetamine use. In 
the third part, two small surveys were used to assess stress (ST-5) and depression (PHQ-9). In the last part, physical parameters, such as weight, height, and waist circumference, and some laboratory results were obtained (Additional file 1, Questionnaire).

According to the World Health Organization (WHO), low-density lipoprotein cholesterol (LDL-C) levels was classified into two main groups: normal $(<100 \mathrm{mg} / \mathrm{dL})$ and abnormal $(\geq 100 \mathrm{mg} / \mathrm{dL})$ [21]. Abnormal LDL-C levels was classified into four levels: near or above optimal (100-129 $\mathrm{mg} / \mathrm{dL})$, borderline high (130-159 mg/dL), high (160-189 $\mathrm{mg} / \mathrm{dL})$, and very high $(\geq 190 \mathrm{mg} / \mathrm{dL})$ [21]. Total cholesterol was classified into three levels: desirable $(<200 \mathrm{mg} / \mathrm{dL})$, borderline high $(200-239 \mathrm{mg} / \mathrm{dL})$, and high $(\geq 240 \mathrm{mg} / \mathrm{dL})$ [21]. High-density lipoprotein cholesterol (HDL-C) was classified into three groups: low $(<40 \mathrm{mg} / \mathrm{dL})$, normal $(40-$ $59 \mathrm{mg} / \mathrm{dL})$, and high $(\geq 60 \mathrm{mg} / \mathrm{dL})$ [21]. Body mass index (BMI) was classified into three groups: underweight $\left(\leq 18.09 \mathrm{~km} / \mathrm{m}^{2}\right)$, normal weight $\left(18.10-22.99 \mathrm{~km} / \mathrm{m}^{2}\right)$, and overweight $\left(\geq 23.00 \mathrm{~km} / \mathrm{m}^{2}\right)$ [22].

The questionnaire was validated by the item objective congruence (IOC) method by three external experts who work in the field: one medical doctor, one public health professional, and one epidemiologist. Then, the questionnaire was tested for reliability by testing 20 selected participants who had similar characteristics as the study population in two hill tribe villages in Muang District, Chiang Rai Province, Thailand. In the process of performing the pilot test, the feasibility, understandability and sequence of the questions were tested. After the pilot test, the second test was performed after revising all issues identified in the pilot test.

According to the process of gathering data in the field, access to the villages was granted by the local governments. After the study, all targeted village headmen were contacted and provided with brief information about the study. Village headmen helped to obtain the list of people living in selected villages. All people who met the study criteria made appointments for data and blood specimen collection at least 3 days in advance. On the date of data collection, all participants were provided with all the information of the study by village health volunteers who were fluent in both Thai and local hill tribe languages. All participants were asked to sign the consent form before providing 3-mL blood specimens. Those who did not follow the 12-h fasting guidelines before blood specimen collection were excluded from the study. Physical examination was performed and was followed by completion of the questionnaire. Blood pressure was measured in the seated position twice in each individual by manual procedure with a 10 -min gap between. However, in any case that had a large difference between the first and the second time, the third time was assessed with a 5-min gap from the second round.
Participants' blood pressure was assessed by one research team who had 7 years of working experience as a professional nurse. During the completion of the questionnaire, the health volunteers were asked to help with translation in case the participants needed help. The total process lasted for $25 \mathrm{~min}$ for each participant. Specimens were kept in a proper box in the field and transferred to the laboratory for analysis on the same day.

All laboratory procedures were performed at the Mae Fah Luang University Medical Laboratory Center. LDL$\mathrm{C}$ and HDL-C levels were assessed by a direct clearance method, while total cholesterol was assessed by the cholesterol oxidase method. Triglycerides were assessed by the glycerol phosphate oxidase peroxidase (GPO-PAP) method. The latex enhanced immunoturbidimetric method was used for HbA1c detection. All lipid profiles and HbA1c assessments were performed by a standard machine, RANDOX ${ }^{@}$, which is certified by the National Glycohemoglobin Standardization Program (NGSP).

Primarily, questionnaires were coded and double entered into an Excel sheet. The data file was then transferred into the $R$ program ( $\mathrm{R} 4.00,2020$ ) for analysis. Descriptive statistics were used to explain the general characteristics of participants: continuous data (mean and SD) and categorical data (percentages). Pearson correlation was used to assess the correlations between LDL-C levels and other key markers, such as age, systolic blood pressure (SBP), diastolic blood pressure (DBP), triglyceride levels, HDL-C levels, and HbA1C levels. A chi-square test was used to detect the associations between the levels of different kinds of lipids. The $\mathrm{t}$-test was used to detect the mean differences in HDL-C and LDL-C levels between sexes in 6 tribes. Moreover, logistic regression was used to determine the associations between independent variables or exposures and abnormal LDL-C levels (LDL-C $\geq 100 \mathrm{mg} / \mathrm{dL}$ ) at a significance level of $\alpha=0.05$.

\section{Results}

A total of 2552 participants were recruited into the analysis with no people refused to the study; $65.9 \%$ were females, $64.1 \%$ were younger than 60 years $($ mean $=54.1$, $\mathrm{SD}=13.1$ ), and $79.5 \%$ were married. Most participants were Buddhist (54.2\%), had no education (76.7\%), worked as an agriculturist (48.7\%), and had an annual family income equal to or less than 50,000 baht. Onefourth (24.3\%) were smokers, $23.4 \%$ used alcohol, $60.8 \%$ did not exercise, $60.7 \%$ were overweight according to their BMI, $49.5 \%$ were obese according to their waist circumference, and $18.6 \%$ had moderate to high levels of stress. A large proportion (90.4\%) consumed moderate to high quantities of salt, $90.3 \%$ used moderate to high levels of monosodium glutamate, and $81.4 \%$ used 
moderate to high levels of lard for their daily cooking (Table 1).

According to LDL-C levels, $69.6 \%$ had abnormal LDLC; $33.6 \%$ had a level from 100 to $129 \mathrm{mg} / \mathrm{dL}$ (above optimal), $24.3 \%$ had a level from 130 to $159 \mathrm{mg} / \mathrm{dL}$ (borderline high), $8.0 \%$ had a level from 160 to $189 \mathrm{mg} / \mathrm{dL}$ (high), and $3.7 \%$ had a level equal to or greater than $190 \mathrm{mg} / \mathrm{dL}$ (very high). Additionally, the proportion of abnormal LDL-C according to sex $(p$-value $=0.533)$ and age categories $(p$ value $=0.908$ ) were not significantly different.

In the univariate model, five factors were found to be associated with high LDL-C levels among the participants: tribe, occupation, amount of monosodium glutamate used for cooking, amount of lard used for daily cooking, BMI, and HbA1C. After controlling for sex, age, religion, education, annual family income, and marital status in the multivariate model, three variables were found to be associated with high LDL-C levels; occupation, the amount of lard use in daily cooking, and HbA1C. Those who were working as agriculturalist had a greater chance of having abnormal LDL-C levels than those traders and other with 1.34 times $(95 \% \mathrm{CI}=1.09$ 1.34). Those who used moderate and high quantities of lard in their daily cooking practice had a greater chance of having abnormal LDL-C levels than those who used low quantities, with 1.45 -times $(95 \% \mathrm{CI}=1.15-1.82)$ and 1.32-times (95\% CI $=1.04-1.68)$ greater likelihoods, respectively. Those who had abnormal HbA1C were less likely to develop abnormal LDL-C levels than those who had normal HbA1C $(\mathrm{AOR}=0.69,95 \% \mathrm{CI}=0.51-0.92)$ (Table 1).

Regarding the correlations between triglycerides and other biomarkers, LDL-C levels were found to be significantly correlated with HbA1c $(r=0.039, p$-value $<0.050)$, HDL-C $(r=-0.244, \quad p$-value $<0.001)$, and triglyceride levels $(r=-0.099, p$-value $<0.001)$. However, when the data were classified by sex, only one variable was found to have a statistically significant correlation with LDL-C levels in males, i.e., triglycerides $(r=-0.099, p$-value $<$ 0.001 ), and four variables were found to have statistically significant correlations with LDL-C levels in females, i.e., SBP $(r=0.049, p$-value $=0.046), \mathrm{HbA1C}$ levels $(r=0.073$, $p$-value $=0.003), \quad$ HDL-C levels $(\mathrm{r}=0.237, \quad p$-value $<$ $0.001)$, and triglyceride levels $(\mathrm{r}=-0.081, p$-value $=$ 0.001) (Table 2).

When HDL-C and LDL-C levels were assessed in closer detail, it was found that a large proportion (17.4\%) had low HDL-C levels $(<40 \mathrm{mg} / \mathrm{dL})$ and elevated or abnormal LDL-C levels ( $\geq 100 \mathrm{mg} / \mathrm{dL})$. Another $14.9 \%$ had high triglyceride and LDL-C levels. However, there were statistically significant differences between the proportions of the different levels of these lipids among the participants (Table 3). Karen people had the highest mean HDL-C levels $(50.08 \mathrm{mg} / \mathrm{dL})$, followed by Yao
$(49.26 \mathrm{mg} / \mathrm{dL})$ and Lisu people $(45.70 \mathrm{mg} / \mathrm{dL})$. Only the Lahu tribe had a significant difference in the mean HDL-C levels between males and females ( $p$-value $=$ $0.003)$. The highest mean LDL-C levels were found in the Karen tribe $(122.22 \mathrm{mg} / \mathrm{dL})$, followed by the Hmong $(120.15 \mathrm{mg} / \mathrm{dL})$ and Akha $(119.96 \mathrm{mg} / \mathrm{dL})$ tribes. And only the Hmong tribe had a significant difference in the mean HDL-C levels between males and females ( $p$ value $=0.025)($ Table 4$)$.

\section{Discussion}

The hill tribe people aged 30 years and over in this study had low levels of education and low economic statuses. A large proportion of the participants did not exercise and were overweight, and one-fourth of the participants used substances. Most of the participants favored salty foods and used a large amount of lard for their daily cooking practice. The prevalence of high-to-very-high LDL-C levels was $60.7 \%$. Additionally, daily lard use for cooking practice was determined to be a risk factor for high LDL-C levels among hill tribe people.

The prevalence of abnormal LDL-C levels among hill tribe people aged 30 years and above was high and higher than that among people in Iran [23], which was reported as $40.0 \%$. Al-Hassan et al. [24] also reported that the prevalence of abnormal HDL-C levels was $12.8 \%$. However, a study conducted in northwestern China [25] found that the prevalence of abnormal LDLC levels was $60.9 \%$, which was close to that in our study. The prevalence of Thai adults was reported to be $29.6 \%$ (29.5\% in males and $29.5 \%$ in females) [20]. Aekplakorn et al. [20] also reported that people who lived in urban areas such as Bangkok (42.2\%) had the highest risk of having high LDL-C levels, followed by people who lived in southern, central, and northern Thailand. This reflects that people living in urban areas are more likely to have high LDL-C levels than those who live in rural areas. However, it is very specific to hill tribe people, who reported an overall prevalence of high LDL-C levels of $60.9 \%$ among people aged 30 years and over. This may be due to the diet of the hill tribe people and other lifestyle factors associated with the Chinese culture since they migrated from China and still have many practices based on their original culture. Moreover, the classification of LDL-C is important to classify the outcome of a study. Different guidelines from different institutes suggest different patterns of LDL-C classification.

The finding in our study was presented that some category of occupation had a greater chance of having abnormal LDL-C levels than another category; those who worked in agricultural sector and unemployed group had a greater chance of having abnormal LDL-C levels than those traders. While looking closer in the income among three occupations, it was found that $92.7 \%$ of 
Table 1 Factors associated with LDL-cholesterol in univariable and multivariable analyses

\begin{tabular}{|c|c|c|c|c|c|c|c|c|c|}
\hline \multirow[t]{2}{*}{ Factors } & \multirow{2}{*}{$\begin{array}{l}\text { Total } \\
\text { n (\%) }\end{array}$} & \multicolumn{2}{|c|}{ LDL-cholesterol } & \multirow[t]{2}{*}{ OR } & \multirow[t]{2}{*}{$95 \% \mathrm{Cl}$} & \multirow[t]{2}{*}{$p$-value } & \multirow[t]{2}{*}{ AOR } & \multirow[t]{2}{*}{$95 \% \mathrm{Cl}$} & \multirow[t]{2}{*}{$p$-value } \\
\hline & & $\begin{array}{l}\text { Abnormal } \\
\text { n (\%) }\end{array}$ & $\begin{array}{l}\text { Normal } \\
\mathrm{n}(\%)\end{array}$ & & & & & & \\
\hline Total & $2552(100)$ & $1778(69.7)$ & $774(30.3)$ & N/A & N/A & N/A & & & \\
\hline \multicolumn{10}{|l|}{ Sex } \\
\hline Male & $870(34.1)$ & $613(70.5)$ & $257(29.5)$ & 1.06 & $0.89-1.27$ & 0.553 & & & \\
\hline Female & $1682(65.9)$ & 1165 (69.3) & $517(30.7)$ & 1.00 & & & & & \\
\hline \multicolumn{10}{|l|}{ Age (years) } \\
\hline $30-39$ & $368(14.4)$ & $260(70.7)$ & $108(29.3)$ & 1.00 & & & & & \\
\hline $40-49$ & 619 (24.3) & $423(68.3)$ & 196 (31.7) & 0.45 & $0.68-1.19$ & 0.446 & & & \\
\hline $50-59$ & $649(25.4)$ & $455(70.1)$ & 194 (29.9) & 0.86 & $0.74-1.29$ & 0.855 & & & \\
\hline $60-69$ & $578(22.6)$ & $402(69.6)$ & $176(30.4)$ & 0.72 & $0.71-1.26$ & 0.718 & & & \\
\hline $70-79$ & 271 (10.6) & $188(69.4)$ & 83 (30.6) & 0.73 & $0.67-1.33$ & 0.727 & & & \\
\hline$\geq 80$ & $67(2.6)$ & $50(74.6)$ & $17(25.4)$ & 0.51 & $0.67-2.21$ & 0.509 & & & \\
\hline \multicolumn{10}{|l|}{ Tribe } \\
\hline Akha & $714(28.0)$ & $514(72.0)$ & $200(28.0)$ & 1.00 & & & & & \\
\hline Lahu & 391 (15.3) & $257(65.7)$ & $134(34.3)$ & 0.75 & $0.57-0.97$ & $0.031^{*}$ & & & \\
\hline Hmong & $389(15.2)$ & $281(72.2)$ & $108(27.8)$ & 1.01 & $0.77-1.33$ & 0.930 & & & \\
\hline Yao & $368(14.4)$ & $247(67.1)$ & $121(32.9)$ & 0.79 & $0.61-1.04$ & 0.097 & & & \\
\hline Karen & $408(16.0)$ & $289(70.8)$ & $119(29.2)$ & 0.95 & $0.72-1.24$ & 0.680 & & & \\
\hline Lisu & $282(11.1)$ & $190(67.4)$ & $92(32.6)$ & 0.80 & $0.60-1.08$ & 0.150 & & & \\
\hline \multicolumn{10}{|l|}{ Religion } \\
\hline Buddhist & $1383(54.2)$ & $966(69.8)$ & 417 (30.2) & 1.00 & & & & & \\
\hline Christ and Muslim & $1169(45.8)$ & $812(69.5)$ & $357(30.5)$ & 0.98 & $0.83-1.16$ & 0.832 & & & \\
\hline \multicolumn{10}{|l|}{ Education } \\
\hline No education & $1957(76.7)$ & $1355(69.2)$ & $602(30.8)$ & 1.00 & & & & & \\
\hline Primary school & $365(14.3)$ & $255(69.9)$ & $110(30.1)$ & 1.03 & $0.81-1.31$ & 0.812 & & & \\
\hline Secondary school or higher & $230(9.0)$ & $168(73.0)$ & $62(27.0)$ & 1.20 & $0.88-1.64$ & 0.236 & & & \\
\hline \multicolumn{10}{|l|}{ Occupation } \\
\hline Unemployed & $628(24.6)$ & $441(70.2)$ & $187(29.8)$ & 1.24 & $0.98-1.57$ & 0.067 & 1.26 & 0.98 .1 .61 & 0.070 \\
\hline Agriculturist & $1243(48.7)$ & $891(71.7)$ & $352(28.3)$ & 1.33 & $1.09-1.63$ & $0.005^{*}$ & 1.34 & $1.09-1.64$ & $0.006^{*}$ \\
\hline Trader and other & $681(26.7)$ & $446(65.5)$ & $235(34.5)$ & 1.00 & & & 1.00 & & \\
\hline \multicolumn{10}{|l|}{ Annual income (baht) } \\
\hline$\leq 50,000$ & $1816(71.2)$ & $1271(70.0)$ & $545(30.0)$ & 1.00 & & & & & \\
\hline $50,001-100,000$ & $527(20.7)$ & $358(67.9)$ & $169(32.1)$ & 0.91 & $0.74-1.12$ & 0.366 & & & \\
\hline$\geq 100,001$ & $209(8.2)$ & $149(71.3)$ & $60(28.7)$ & 1.07 & $0.78-1.46$ & 0.697 & & & \\
\hline \multicolumn{10}{|l|}{ Marital status } \\
\hline Single & $138(5.4)$ & $103(74.6)$ & $35(25.4)$ & 1.00 & & & & & \\
\hline Married & 2039 (79.9) & 1415 (69.4) & $624(30.6)$ & 0.77 & $0.52-1.14$ & 0.196 & & & \\
\hline Ever married & $375(14.7)$ & $260(69.3)$ & $115(30.7)$ & 0.77 & $0.49-1.19$ & 0.242 & & & \\
\hline \multicolumn{10}{|l|}{ Smoking } \\
\hline No & $1932(75.7)$ & $1350(69.9)$ & $582(30.1)$ & 1.00 & & & & & \\
\hline Yes & $620(24.3)$ & $428(69.0)$ & $192(31.0)$ & 0.96 & $0.79-1.17$ & 0.691 & & & \\
\hline
\end{tabular}


Table 1 Factors associated with LDL-cholesterol in univariable and multivariable analyses (Continued)

\begin{tabular}{|c|c|c|c|c|c|c|c|c|c|}
\hline \multirow[t]{2}{*}{ Factors } & \multirow{2}{*}{$\begin{array}{l}\text { Total } \\
\text { n (\%) }\end{array}$} & \multicolumn{2}{|c|}{ LDL-cholesterol } & \multirow[t]{2}{*}{ OR } & \multirow[t]{2}{*}{$95 \% \mathrm{Cl}$} & \multirow[t]{2}{*}{$p$-value } & \multirow[t]{2}{*}{ AOR } & \multirow[t]{2}{*}{$95 \% \mathrm{Cl}$} & \multirow[t]{2}{*}{$p$-value } \\
\hline & & $\begin{array}{l}\text { Abnormal } \\
\text { n (\%) }\end{array}$ & $\begin{array}{l}\text { Normal } \\
\text { n (\%) }\end{array}$ & & & & & & \\
\hline \multicolumn{10}{|l|}{ Alcohol use } \\
\hline No & $1955(76.6)$ & $1364(69.8)$ & $591(30.2)$ & 1.00 & & & & & \\
\hline Yes & $597(23.4)$ & $414(69.3)$ & $183(30.7)$ & 0.98 & $0.80-1.20$ & 0.844 & & & \\
\hline \multicolumn{10}{|l|}{ Exercise } \\
\hline No & $1551(60.8)$ & $1078(69.5)$ & $473(30.5)$ & 1.12 & $0.86-1.47$ & 0.407 & & & \\
\hline Sometimes & $719(28.2)$ & $511(71.1)$ & $208(28.9)$ & 1.21 & $0.90-1.63$ & 0.209 & & & \\
\hline Regularly & $282(11.1)$ & $189(67.0)$ & $93(33.0)$ & 1.00 & & & & & \\
\hline \multicolumn{10}{|c|}{ Amount of salt use for cooking } \\
\hline Low & $244(9.6)$ & $160(65.6)$ & $84(34.4)$ & 1.00 & & & & & \\
\hline Moderate & $1115(43.7)$ & $788(70.7)$ & $327(29.3)$ & 1.27 & $0.94-1.70$ & 0.117 & & & \\
\hline High & $1193(46.7)$ & $830(69.6)$ & $363(30.4)$ & 1.20 & $0.90-1.61$ & 0.219 & & & \\
\hline \multicolumn{10}{|c|}{ Amount of monosodium glutamate use for cooking } \\
\hline Low & $248(9.7)$ & $159(64.1)$ & $89(35.9)$ & 1.00 & & & & & \\
\hline Moderate & $1006(39.4)$ & $712(70.8)$ & $294(29.2)$ & 1.36 & $1.01-1.82$ & $0.042^{*}$ & & & \\
\hline High & $1298(50.9)$ & $907(69.9)$ & $391(30.1)$ & 1.30 & $0.98-1.73$ & 0.073 & & & \\
\hline \multicolumn{10}{|c|}{ Amount of lard used for cooking } \\
\hline Low & $476(18.7)$ & $304(63.9)$ & $172(36.1)$ & 1.00 & & & 1.00 & & \\
\hline Moderate & $1214(47.6)$ & $872(71.8)$ & $342(28.2)$ & 1.44 & $1.15-1.81$ & $0.001^{*}$ & 1.45 & $1.15-1.82$ & $0.001^{*}$ \\
\hline High & $862(33.8)$ & $602(69.8)$ & $260(30.2)$ & 1.31 & $1.03-1.66$ & $0.025^{*}$ & 1.32 & $1.04-1.68$ & $0.025^{*}$ \\
\hline \multicolumn{10}{|l|}{ Stress (ST-5) } \\
\hline Low & 2076 (81.3) & $1441(69.4)$ & 635 (30.6) & 1.00 & & & & & \\
\hline Moderate & $399(15.6)$ & $280(70.2)$ & 119 (29.8) & 1.04 & $0.82-1.31$ & 0.762 & & & \\
\hline High & $77(3.0)$ & $57(74.0)$ & $20(26.0)$ & 1.26 & $0.75-2.11$ & 0.388 & & & \\
\hline \multicolumn{10}{|l|}{ Depression } \\
\hline No & 2245 (88.0) & $1564(69.7)$ & $681(30.3)$ & 1.00 & & & & & \\
\hline Yes & 307 (12.0) & $214(69.7)$ & $93(30.3)$ & 1.00 & $0.77-1.30$ & 0.988 & & & \\
\hline \multicolumn{10}{|l|}{ BMI } \\
\hline Normal weight & $196(7.7)$ & $131(66.8)$ & 65 (33.2) & 1.00 & & & & & \\
\hline Underweight & 807 (31.6) & $555(68.8)$ & $252(31.2)$ & 0.52 & $0.38-0.72$ & $<0.001^{*}$ & & & \\
\hline Overweight & 1549 (60.7) & $1092(70.5)$ & $457(29.5)$ & 1.18 & $0.86-1.61$ & 0.292 & & & \\
\hline \multicolumn{10}{|l|}{ Waistline } \\
\hline Normal & $1290(50.5)$ & $900(69.8)$ & $390(30.2)$ & 1.00 & & & & & \\
\hline Obese & $1262(49.5)$ & 878 (69.6) & $384(30.4)$ & 0.99 & $0.83-1.17$ & 0.915 & & & \\
\hline \multicolumn{10}{|l|}{ HbA1c (mg/dl) } \\
\hline Normal $(<6.5)$ & 2349 (92.0) & $1652(70.3)$ & $697(29.7)$ & 1.00 & & & 1.00 & & \\
\hline Abnormal ( $\geq 6.5)$ & $203(8.0)$ & $126(62.1)$ & 77 (37.9) & 0.69 & $0.51-0.93$ & $0.014^{*}$ & 0.69 & $0.51-0.92$ & $0.013^{*}$ \\
\hline
\end{tabular}

* Binary logistic regression was used to detect the associations at significance level $a=0.05$

unemployed group had their annual income $\leq 100,000$ baht, $88.7 \%$ of agriculturist had their annual income $\leq 100,000$ baht, while only $66.6 \%$ of traders had their annual income $\leq 100,000$ baht. This is supported by a study conducted in Chili which presented that lower income led to have high stress, and accelerated abnormal of
LDL-C levels eventually [26]. Moreover, this finding was consisted with a study conducted in Thailand, which reported that working as agriculturalist contributed in the abnormal of LDL-C levels significantly [27]. A study in North American and Europe was clearly presented on the association between some categories of occupation 
Table 2 Correlations between LDL and key-biomarkers among the participants

\begin{tabular}{llllllll}
\hline Group & Statistics & Age & SBP & DBP & HbA1C & HDL-C & Triglyceride \\
\hline Total & $\mathbf{r}$ & $\mathbf{0 . 0 1 5}$ & $\mathbf{0 . 0 2 3}$ & $\mathbf{0 . 0 2 3}$ & $\mathbf{0 . 0 3 9}$ & $\mathbf{0 . 2 4 4}$ & -0.099 \\
& $(p$-value $)$ & $(0.457)$ & $(0.246)$ & $(0.242)$ & $\left(0.050^{*}\right)$ & $\left(<0.001^{*}\right)$ & $\left(<0.001^{*}\right)$ \\
Male & $\mathrm{r}$ & $\mathbf{0 . 0 1 2}$ & -0.027 & 0.000 & -0.032 & 0.260 & -0.136 \\
& $(p$-value $)$ & $(0.721)$ & $(0.421)$ & $(0.988)$ & $(0.073)$ & $(0.237)$ & $\left(<0.001^{*}\right)$ \\
Female & $\mathrm{r}$ & $\mathbf{0 . 0 1 5}$ & $\mathbf{0 . 0 4 9}$ & $\mathbf{0 . 0 3 6}$ & $\mathbf{0 . 0 7 3}$ & $\mathbf{0 . 2 3 7}$ & -0.081 \\
& $(p$-value $)$ & $(0.534)$ & $\left(0.046^{*}\right)$ & $(0.144)$ & $\left(0.003^{*}\right)$ & $\left(<0.001^{*}\right)$ & $\left(0.001^{*}\right)$ \\
\hline
\end{tabular}

*Spearman's correlation was used to detect the correlations between variables at the significant level a $=0.05$; SBP Systolic blood pressure; DBP Diastolic blood pressure; HDL-C High density lipoprotein cholesterol; LDL-C Low density lipoprotein cholesterol; HbA1c Glycosylated hemoglobin

and abnormal LDL-C levels especially those who were working under high stress and low paid such as agriculturists [28]. Another study in remote areas in Australia, it was found that those who were agricultural workers had a greater chance of having abnormal LDL-C levels than other groups significantly [29].

In our study, it was found that the quantity of lard use was associated with abnormal LDL-C levels among hill tribe people aged 30 years and over. Normally, the hill tribe people use animal oil for cooking (lard) [13], and use a large amount of lard in their practice which is similar to Chinese cooking style. This specific cooking practice is supported by their origin in China before moving down to Thailand a long a couple centuries [13, 16]. In China, the environmental temperature is average in low, then having high volume of cooking oil in daily life is common to maintain body temperature. However, in their current living environment in Thailand where are a tropical zone, the environmental temperature is higher than in China but the hill tribe people still eating high volume of cooking oil. Then, this could lead overweight $(60.7 \%)$ and having abnormal LDL-C levels. Very interestingly, after seeking other studies in both Thai and English from different sources of medical and public health sciences databased, there is no scientific information relevant to quantity of lard and LDL-C levels available.
In our study, it was also found that LDL-C levels had a positive correlation with $\mathrm{HbA1C}$ and a negative correlation with HDL-C and triglycerides. A closer examination revealed that LDL-C levels had a negative correlation only with triglycerides and had positive correlations with SBP, HbA1C, HDL-C levels, and triglycerides in females. This was supported by a study conducted by Bhattacharjee et al. [30] that reported that LDL-C levels was significantly correlated with $\mathrm{HbA1C}$ in a positive direction among myocardial infarction patients. A study among diabetes patients in Iran found that LDL-C levels was significantly positively correlated with both DBP and SBP [31]. Another study in Poland [32] showed that LDL-C levels and triglycerides levels had a positive correlation with triglycerides in both male and female participants. A study in the United States [33] and a study in Japan [34] also clearly demonstrated the positive correlation of LDL-C levels with both DBP and SBP. This may be most the hill tribe people consume a large amount of lard in daily life but a few proportions have regular exercise (11.1\%). Moreover, according to the BMI, $60.7 \%$ were classified as overweight which is a good indicator that the hill tribe people have high cooking oil dietary and low physical activity problems.

A few limitations were found in this study. The language barrier was the major problem in the study; however, the language barrier was addressed by the village

Table 3 Associations LDL-C according to HDL-C, total cholesterol, and triglycerides

\begin{tabular}{|c|c|c|c|c|c|c|c|}
\hline \multirow[t]{2}{*}{ Lipids } & \multirow{2}{*}{$\begin{array}{l}\text { Levels } \\
\text { (mg/dL) }\end{array}$} & \multicolumn{5}{|c|}{ LDL-C (mg/dL) } & \multirow{2}{*}{$\begin{array}{l}x^{2} \\
\text { (p-value) }\end{array}$} \\
\hline & & $<100$ & $100-129$ & $130-159$ & $160-189$ & $\geq 190$ & \\
\hline \multirow[t]{3}{*}{ HDL-C } & $<40$ & $362(44.9)$ & $278(34.5)$ & $143(17.7)$ & $18(2.2)$ & $5(0.6)$ & \multirow[t]{3}{*}{$<0.001^{*}$} \\
\hline & $40-59$ & $358(24.1)$ & $472(28.8)$ & $423(28.5)$ & $165(11.1)$ & $66(4.4)$ & \\
\hline & $\geq 60$ & 54 (20.6) & 107 (40.8) & $55(21.0)$ & $22(8.4)$ & $24(9.2)$ & \\
\hline \multirow[t]{3}{*}{ Total cholesterol } & $<200$ & $697(49.0)$ & 563 (39.6) & $153(10.8)$ & $9(0.6)$ & $0(0.0)$ & \multirow[t]{3}{*}{$<0.001^{*}$} \\
\hline & $200-239$ & $29(4.0)$ & $264(36.1)$ & $346(47.3)$ & $81(11.1)$ & $11(1.5)$ & \\
\hline & $\geq 240$ & $48(12.0)$ & $30(7.5)$ & $122(30.6)$ & $115(28.8)$ & $84(21.1)$ & \\
\hline \multirow[t]{3}{*}{ Triglycerides } & $<150$ & $427(28.7)$ & $508(34.1)$ & $375(25.2)$ & $116(7.8)$ & $62(4.2)$ & \multirow[t]{3}{*}{$<0.001^{*}$} \\
\hline & 150-199 & 80 (19.1) & $142(34.0)$ & 135 (32.3) & $46(11.0)$ & $15(3.6)$ & \\
\hline & $200-499$ & $267(41.3)$ & 207 (32.0) & $111(17.2)$ & $43(6.7)$ & $18(2.8)$ & \\
\hline
\end{tabular}

${ }^{*}$ Chi-square was used to detect the associations at the significant level $a=0.05$ 
Table 4 The HDL-C and LDL-C levels in different tribes

\begin{tabular}{|c|c|c|c|c|c|c|c|c|c|}
\hline \multirow[t]{2}{*}{ Tribe } & \multirow[t]{2}{*}{ Sex } & \multicolumn{2}{|l|}{ HDL-C } & \multirow{2}{*}{$\begin{array}{l}\mathrm{t}- \\
\text { test }\end{array}$} & \multirow[t]{2}{*}{$p$-value } & \multicolumn{2}{|l|}{ LDL-C } & \multirow[t]{2}{*}{ t-test } & \multirow[t]{2}{*}{$p$-value } \\
\hline & & $\begin{array}{l}\text { Mean } \\
(\mathrm{mg} / \mathrm{dL})\end{array}$ & SD & & & $\begin{array}{l}\text { Mean } \\
(\mathrm{mg} / \mathrm{dL})\end{array}$ & SD & & \\
\hline \multirow[t]{3}{*}{ Akha } & Total & 44.57 & 11.24 & & & 119.96 & 34.02 & & \\
\hline & Male & 44.29 & 10.47 & -0.46 & 0.646 & 121.44 & 33.36 & 0.79 & 0.430 \\
\hline & Female & 44.71 & 11.58 & & & 119.28 & 34.33 & & \\
\hline \multirow[t]{3}{*}{ Lahu } & Total & 41.16 & 10.71 & & & 115.89 & 36.51 & & \\
\hline & Male & 38.98 & 9.67 & -2.97 & $0.003^{*}$ & 113.56 & 35.29 & -0.92 & 0.358 \\
\hline & Female & 42.33 & 11.06 & & & 117.13 & 37.15 & & \\
\hline \multirow[t]{3}{*}{ Hmong } & Total & 43.53 & 11.27 & & & 120.15 & 36.23 & & \\
\hline & Male & 43.55 & 10.31 & 0.034 & 0.973 & 125.54 & 37.90 & 2.25 & $0.025^{*}$ \\
\hline & Female & 43.51 & 11.82 & & & 117.02 & 34.92 & & \\
\hline \multirow[t]{3}{*}{ Yao } & Total & 49.26 & 13.14 & & & 118.08 & 34.64 & & \\
\hline & Male & 48.49 & 13.21 & -0.74 & 0.462 & 119.44 & 33.12 & 0.49 & 0.625 \\
\hline & Female & 49.59 & 13.12 & & & 117.50 & 35.31 & & \\
\hline \multirow[t]{3}{*}{ Karen } & Total & 50.08 & 12.44 & & & 122.22 & 35.84 & & \\
\hline & Male & 50.01 & 13.68 & -0.09 & 0.926 & 121.78 & 36.00 & -0.19 & 0.852 \\
\hline & Female & 50.13 & 11.72 & & & 122.47 & 35.82 & & \\
\hline \multirow[t]{3}{*}{ Lisu } & Total & 45.70 & 11.19 & & & 117.73 & 36.41 & & \\
\hline & Male & 44.99 & 11.88 & -0.85 & 0.398 & 113.78 & 38.19 & -1.45 & 0.148 \\
\hline & Female & 46.15 & 10.75 & & & 120.22 & 35.13 & & \\
\hline
\end{tabular}

* T-test was used to detect the associations at significance level $a=0.05$

heath volunteers who were trained for at least $1 \mathrm{~h}$ to understand the whole content of the questionnaire before starting the interview. Second, some significant variables in the questionnaire were not clearly categorized before assessment in the field, such as the type and frequency of smoking and the frequency and volume of drinking alcohol, which could impact the interpretations of the findings. In addition, some measures assessing the volume of lard, salts, and monosodium glutamate used are difficult to apply for the hill tribe context, which has various cooking practices, including different sizes of utensils used and different family members having food each time. The accuracy of measurements in terms of health behaviors and cooking practices are of great concern to all studies while working in hill tribe people. In addition, the interpretation of the correlations between LDL-C and key biomarkers can be more informative by accounting for total calories and total saturated fat intake, visceral obesity and insulin resistance.

\section{Conclusion}

The hill tribe people in Thailand are working in the agricultural sector and often live with poor economic status and illiteracy. They do not exercise in daily life and favor salty food and heavy use lard for cooking practice. Moreover, a large proportion of these individuals are overweight with high LDL-C levels. These individuals are at high risk of developing cardiovascular diseases that could lead to several complications and eventually require health care services. Therefore, effective public health interventions should be implemented for the population to improve personal health behaviors and to reduce the quantity of lard and salt used in daily cooking practices. Additionally, these individuals should be educated on healthy behaviors, a healthy diet and exercise to reduce the likelihood of having health problems related to high LDL-C levels.

\section{Abbreviations}

BMI: Body mass index; Cl: Confident interval; CVD: Cardiovascular diseases; DALYs: Disability-adjusted life years; GDP: Gross domestic product; DBP: Diastolic blood pressure; HbA1C: Glycated hemoglobin; HDL-C: Highdensity lipoprotein cholesterol; IOC: Item objective congruence; LDL-C: Lowdensity lipoprotein cholesterol; OR: Odds ratio; SBP: Systolic blood pressure; SD: Standard deviation; UN: United Nations; WHO: World health Organization

\section{Supplementary Information}

The online version contains supplementary material available at https://doi. org/10.1186/s12889-021-10577-3.

Additional file 1. Questionnaire

\section{Acknowledgements}

We would like to thank Thailand Health System Research Institute (HSRI) and Mae Fah Luang University for support grants. 


\section{Authors' contributions}

NK designed the study, developed research tools, collected data, interpreted the analysis, drafted and approved the manuscript. TA, SK, NK, VK, and CW collected data, analyzed data, drafted and approved the manuscript. RT, PU, FY developed research tool, collected data, collected blood specimen, worked for laboratory analysis, final approved the final manuscript. All authors read and approved the final manuscript.

\section{Funding}

The project was supported by The Health System Research Institute, Thailand (Grant No 61-027). However, the grant funder did not involve in the study.

\section{Availability of data and materials}

The datasets used in the study are available from the corresponding author on reasonable request

\section{Declarations}

\section{Ethics approval and consent to participate}

All the study protocols were by the Mae Fah Luang University Research Ethic Committee on Human Research (No. REH-6100). Before starting interview, all participants were provided all relevant and essential information. Inform consent form was obtained by written in voluntary basis before starting interview.

\section{Consent for publication}

Not applicable.

\section{Competing interests}

The authors declare that they have no competing interests.

\section{Author details}

'School of Health Science, Mae Fah Luang University, Chiang Rai, Thailand. ${ }^{2}$ Center of Excellence for The Hill tribe Health Research, Mae Fah Luang University, Chiang Rai, Thailand. ${ }^{3}$ Chulabhorn Royal Academy, Bangkok, Thailand.

Received: 23 June 2020 Accepted: 7 March 2021

Published online: 12 March 2021

\section{References}

1. World Health Organization $(\mathrm{WHO})$. Global health observatory $(\mathrm{GHO})$ data Available from: https://www.who.int/gho/ncd/risk_factors/cholesterol_text/ en/. Accessed 21 May 2020

2. World Health Organization (WHO). Cardiovascular diseases: key facts. Available from: https://www.who.int/news-room/fact-sheets/detail/cardiova scular-diseases-(cvds). Accessed 21 May 2020.

3. Centers for Disease Control and Prevention (CDC). Cholesterol: high cholesterol facts. Available from: https://www.cdc.gov/cholesterol/facts.htm. Accessed 21 May 2020

4. Maharani SA, Praveen D, Oceandy D, Tampubolon G, Patel A. Cardiovascular disease risk factor prevalence and estimated 10-year cardiovascular risk scores in Indonesia: the SMARThealth extend study. PlosOne. 2019;14(4): e0215219. https://doi.org/10.1371/journal.pone.0215219.

5. Kim MK, Han K, Joung HN, Baek KH, Song KH, Kwon HS. Cholesterol levels and development of cardiovascular disease in Koreans with type 2 diabetes mellitus and without pre-existing cardiovascular disease. BMC Cardiovasc Diabetol. 2019:18(139). https://doi.org/10.1186/s12933-019-0943-9.

6. Krittayaphong R, Phrommintikul A, Boonyaratvej S, Na-Ayudhya RK, Tatsanavivat $\mathrm{P}$, Komoltri $\mathrm{C}$, et al. The rate of patients at high risk for cardiovascular disease with an optimal low-density cholesterol level: a multicenter study from Thailand. J Geriatr Cardiol. 2019;16(4):344-53. https://doi.org/10.11909/j.issn.1671-5411.2019.04.006.

7. World Health Organization (WHO). Prevention of cardiovascular disease. Available from: https://www.who.int/cardiovascular_diseases/guidelines/ PocketGL.ENGLISH.AFR-D-E.rev1.pdf. Accessed 21 May 2020

8. United Nations (UN). Thailand: country profile, 2019. Available from: https:// data.un.org/en/iso/th.html. Accessed 3 June 2020.

9. World Bank. Thailand: economic. Available from: https://www.worldbank org/en/country/thailand. Accessed 3 June 2020.
10. Thailand-World Health Organization (WHO). Thailand: morbidity and mortality rates in 2016. Available from: https://www.who.int/nmh/countries/ tha_en.pdf. Accessed 3 June 2020.

11. Ministry of Public Health. Situation of cardiovascular diseases in 2018 Available from: http://thaincd.com/2016/mission/documents-detail.php?id= 13653\&tid=32\&gid=1-020.

12. World Health Organization (WHO). WHO country cooperation strategy, Thailand: 2017-2021. Available from: https://apps.who.int/iris/handle/10665/2 55510. Accessed 5 June 2020.

13. Princess Maha Chakri Siridhorn Anthropology center. Hill tribe. 2017. http:// www.sac.or.th/main/index.php. Accessed 5 June 2020

14. World Health Organization (WHO). Migrant and vulnerable health program: WHO-Thailand office work-plan 2017. 2016. p.2-6.

15. The Hill tribe Welfare and Development Center, Chiang Rai Province. Hill tribe population. In: The hill tribe welfare and development center. Chiang Rai: Ministry of Social Development and Human Security; 2018. p. 17-25.

16. Apidechkul T, Wongnuch P. Sittisarn S, Ruanjai T. Health status of Akha hill tribe in Chiang Rai Province, Thailand. J Pub Health Dev. 2016;14(1):77-97.

17. Chomchoei C, Apidechkul T, Khunthason S, Kullawong N, Kaewdounglek V, Tamornpark R, et al. Prevalence and factors associated with type 2 diabetes mellitus among middle aged and elderly Lisu hill tribe people, northern Thailand: a cross-sectional study. J Health Sci Altern Med. 2019;1(3):17-23.

18. Apidechkul T. Prevalence and factors associated with type 2 diabetes mellitus and hypertension among the hill tribe elderly population in northern Thailand. BMC Public Health. 2018;18(694). https://doi.org/10.1186/s12889-018-5607-2.

19. Asian Development Bank (ADB). Thailand and ADB: Poverty line. Available from: https://www.adb.org/countries/thailand/poverty. Accessed 11 June 2020

20. Aeplakorn W, Taneepanichskul S, Kessomboon P, Chongsuvivatwong V, Putwatana P, Sritara $P$, et al. Prevalence of dyslipidemia and management in the Thai population, National Health Examination Survey IV, 2009. J Lipids. 2014;2014:1-13. https://doi.org/10.1155/2014/249584.

21. World Health Organization $(\mathrm{WHO})$. Guidelines for the management of dyslipidemia in patients with diabetes mellitus. Available from: http://applica tions.emro.who.int/dsaf/dsa699.pdf. Accessed 18 June 2020.

22. World Health Organization (WHO). Body mass index: BMI. Available from: http://www.euro.who.int/en/health-topics/disease-prevention/nutrition/ahealthy-lifestyle/body-mass-index-bmi. Accessed 18 June 2020.

23. Toor MA, Kiani F, Sayehmiri F, Sayehmiri K, Mohsenzadeh Y, Ostovar R, et al. Iran J Med Sci. 2018;43(5):449-65.

24. Al-Hassan YT, Fabella EL, Estrella E, Aatif M. Prevalence and determinants of dyslipidemia: data from a Saudi University clinic. Open Public Health J. 2018; 11(1):416-24. https://doi.org/10.2174/1874944501811010416.

25. Ge P, Dong C, Ren X, Weiderpass E, Zhang C, Fan H, Zhang J, Zhang Y, Xi J. The high prevalence of low-HDL-cholesterol levels and dyslipidemia in rural populations in northwestern China. PlosOne. 2015;10(2):e0144104. https://doi.org/10.1371/journal.pone.0144104.

26. Lara $\mathrm{M}$, Amigo $\mathrm{H}$. Association between education and blood lipid levels as income increases over a decade: a cohort study. BMC Public Health. 2018; 18(286). https://doi.org/10.1186/s12889-018-5185-3.

27. Kongtip $P$, Nankongnab N, Tipayamongkholgul M, Bunngamchairat A Yimsabai J, Pataitiemthong A, Woskie S. A cross-sectional investigation of cardiovascular and metabolic biomarkers among conventional and organic farmers in Thailand. Int J Environ Res Public Health. 2018;15(2590):1-12. https://doi.org/10.3390/ijerph15112590.

28. Lewin A, Thomas F, Pannier B, Chaix B. Work economic sectors and cardiovascular risk factors: cross-sectional analysis based on the RECORD study. BMC Public Health. 2014;14(750). https://doi.org/10.1186/1471-2458-14-750.

29. Davis-Lameloise $N$, Philpot $B$, Janus ED, Versace $V L$, Laatikainen $T$, Vartiainen EA, et al. Occupational differences, cardiovascular risk factors and lifestyle habits in South Eastern rural Australia. BMC Public Health. 2013;13(1090). https://doi.org/10.1186/1471-2548-13-1090.

30. Bhattacharjee $P$, Das $P$, Nath BK, Basumatary A, Das D. HbA1C and its correlation with lipid profile in acute myocardial infarction. Int J Contemp Med Res. 2018:5(4):13-6.

31. Behradmanesh S, Nasri P. Serum cholesterol and LDL-C in association with level of diastolic blood pressure in type 2 diabetic patients. J Renal Inj Prev. 2012;1(1):23-6. https://doi.org/10.12861/jrip.2012.09.

32. Gierach M, Skowronska A, Gierach J, Junik R. The correlation between LDL-C and non-HDL-C levels and cardiovascular events in patients with metabolic syndrome. Endocrinol Metab Syndr. 2016;5(2). https://doi.org/10.4172/21 61-1017.1000229. 
33. Egan BM, Li J, Qanungo S, Wolfman TE. Blood pressure and cholesterol control in hypertensive hypercholesterolemic patients. Circulation. 2013; 128(2):28-41.

34. Tsukinoki R, Okamura T, Watanabe M, Kokubo Y, Higashiyama A, Nishimura K, Takegami M, Murakami Y, Okayama A, Miyamoto Y. Blood pressure, lowdensity lipoprotein cholesterol, and incidences of coronary artery disease and ischemic stroke in Japanese: the Suita study. Am J Hypertens. 2014; 27(11):1362-9. https://doi.org/10.1093/ajh/hpu059.

\section{Publisher's Note}

Springer Nature remains neutral with regard to jurisdictional claims in published maps and institutional affiliations.

Ready to submit your research? Choose BMC and benefit from:

- fast, convenient online submission

- thorough peer review by experienced researchers in your field

- rapid publication on acceptance

- support for research data, including large and complex data types

- gold Open Access which fosters wider collaboration and increased citations

- maximum visibility for your research: over $100 \mathrm{M}$ website views per year

At $\mathrm{BMC}$, research is always in progress.

Learn more biomedcentral.com/submissions 